\title{
Single-Arm Study to Assess Comprehensive Infusion Guidance for the \\ Prevention and Management of the Infusion Associated Reactions (IARs) in
}

Relapsing-Remitting Multiple Sclerosis (RRMS) Patients Treated With

Alemtuzumab (EMERALD)

\begin{abstract}
Sandra Vukusica,*, David Brassat ${ }^{b}$, Jerome de Sezec, Guillermo Izquierdo ${ }^{d}$, Andreas Lysandropoulos ${ }^{e}$, Wibe Moll ${ }^{\dagger}$, Ludo Vanopdenbosch' ${ }^{g}$, Maria Jesus Arque ${ }^{h}$, Mehdi Kertous i,j, Pascal Rufii,j, Celia Oreja-Guevarak
\end{abstract}

a Service de Neurologie, Sclérose en Plaques, Pathologies de la Myéline et Neuroinflammation, Hôpital Neurologique Pierre Wertheimer, Hospices Civils de Lyon, and Centre de Recherche en Neurosciences de Lyon - INSERM 1028 et CNRS UMR5292, Université Claude Bernard Lyon 1, Lyon, France

b CRC-SEP, Pole des neurosciences CHU Toulouse, and UMR 1043, Université de Toulouse III, Toulouse, France

c Strasbourg University Hospital, Clinical Investigation Center (CIC 1434), UMR 1119 and FMTS, Strasbourg, France

d Department of Neurology, Hospital Universitario Virgen Macarena, Seville, Spain

e Formerly of Department of Neurology, CUB-Hôpital Erasme Route de Lennik 808 1070 Brussels, Belgium; Sanofi, Cambridge, Massachusetts, United States

f Department of Neurology, Maasstad Ziekenhuis, Maasstadweg 213079 DZ

Rotterdam, KvK 24299846, Netherlands

g Department of Neurology, AZ Sint Jan Brugge Oostende, Ruddershove 10, 8000

Brugge, Belgium

h Sanofi, Torre Diagonal Mar, Calle Josep Pla, 2. 08019 Barcelona, Spain

i Sanofi, 1 Avenue Pierre Brossolette 91385, Chilly-Mazarin, France

j Experis Health, Immeuble Eureka, 13 Rue Ernest Renan, 92723 Nanterre, France

k Department of Neurology, Hospital Clínico San Carlos, IdISSC; Departamento de Medicina, Universidad Complutense de Madrid (UCM), Madrid, Spain

Running Title: Management of infusion associated reactions (IARs) with alemtuzumab

Type of Article: Original Research Article

\section{Address correspondence to:}

*Pr Sandra Vukusic,

Service de Neurologie, Sclérose en Plaques, Pathologies de la Myéline et Neuroinflammation, Hôpital Neurologique Pierre Wertheimer

59 boulevard Pinel 69677 BRON cedex - France 
Phone: +33 4726813 10, Facsimile: +33 4723575 25, E-mail: sandra.vukusic@chu-lyon.fr

\section{Study Sponsor:}

Sanofi

Source(s) of support (in the form of grants, equipment, drugs, or all of these): Sanofi

Clinical Trials Registration Number: NCT02205489 
Abbreviations:

AE adverse event

AESI adverse event of special interest

$\beta-H C G \quad$ beta human chorionic gonadotropin

BID twice daily

BVL brain volume loss

CDI confirmed disability improvement

CDW confirmed disability worsening

DMT disease-modifying therapy

EDSS Expanded Disability Status Scale

EOS end of study

FU follow-up

Gr grade

$\mathrm{H}_{1} \quad$ histamine receptor $\mathrm{H} 1$

$\mathrm{H}_{2} \quad$ histamine receptor $\mathrm{H} 2$

IAR infusion-associated reaction

IV intravenous

MRI magnetic resonance imaging

MS multiple sclerosis

NSAID nonsteroidal anti-inflammatory drug.

PO Per os (orally)

RMP Risk Management Plan 
RRMS relapsing remitting multiple sclerosis

SAE serious adverse event

SC subcutaneous

SD standard deviation

SmPC Summary of Product Characteristics

SS safety set

TEAE treatment-emergent adverse event

Treg regulatory $\mathrm{T}$ cell 


\begin{abstract}
Background: Alemtuzumab is a humanized IgG monoclonal antibody approved in more than 60 countries for patients with relapsing remitting multiple sclerosis (RRMS). In phase 2 and 3 clinical trials (CAMMS223 [NCT00050778], CARE-MS I [NCT00530348], and CARE-MS II [NCT00548405]), patients receiving alemtuzumab demonstrated significantly greater improvements on clinical and MRI outcomes versus SC IFN $\beta-1 \mathrm{a}$; mild to moderate infusion-associated reactions (IARs) were the most frequently reported adverse events (AEs) associated with alemtuzumab. EMERALD (NCT02205489) was a phase 4, multicenter, multinational, single-arm study designed to assess an algorithm for the prevention and management of IARs in RRMS patients treated with alemtuzumab.
\end{abstract}

Methods: Patients were treated with a study regimen of enhanced IAR prophylaxis relative to phase 2 and 3 studies. $\mathrm{H}_{1}$ and/or $\mathrm{H}_{2}$ antagonists or equivalent gastroprotection (proton pump inhibitors) were given 1 day before alemtuzumab infusion, 1 hour prior to the infusion, and post-infusion. Methylprednisolone was given orally 1 day before infusion, 1 hour prior to the infusion, and as needed post-infusion. Antipyretics were given 1 hour before infusion and as needed post-infusion. Antiemetics and normal saline were given as needed during and post-infusion.

Results: Of the 61 patients screened, 58 (95.1\%) were enrolled into the study. Of the 58 patients who received the first infusion of Period 1, 57 (98.3\%) completed the 5 days of Course 1. A total of 54 patients received the first infusion of Period 2 and 53 completed 
the 3-day course. All patients $(n=58)$ completed the Month 6 visit and 54 the Month 12 visit. 93.1\% of patients had at least one IAR (91.4\% in Period 1 and $81.5 \%$ in Period 2), the majority of which were grade $1(69.1 \%)$ or grade $2(28.0 \%)$. The three most common IARs of headache, pyrexia, and rash occurred in $48.8 \%, 40.7 \%$, and $24.1 \%$ of patients during the first course and $14.8 \%, 17.2 \%$, and $5.6 \%$ of patients during the second course, respectively. The majority of IARs occurred within 6 hours after the start of alemtuzumab infusion, with a peak during the first 2 hours. The types and overall incidence of IARs were consistent with phase 2 and 3 trials. Frequency and distribution of rash were reduced in the EMERALD study compared with previous clinical trials. Serious IARs occurred in $15.5 \%$, a higher rate than reported in clinical trials of alemtuzumab.

Conclusion: Although most alemtuzumab-treated patients experienced IARs as in previous controlled clinical studies, there was an improvement in the frequency and distribution of alemtuzumab-associated rash, which may have been associated with this study's prophylaxis regimen.

\section{Key words:}

Alemtuzumab

Multiple sclerosis

Induction therapy

Infusion-associated reaction (IAR)

Rash

Methylprednisolone treatment 


\section{Introduction}

Alemtuzumab is a humanized monoclonal antibody that selectively binds to CD52 to deplete circulating T and B lymphocytes (Hu et al., 2009). After lymphocyte depletion, a distinctive pattern of $\mathrm{T}$ - and $\mathrm{B}$-cell repopulation begins within weeks. The immunomodulatory effects of alemtuzumab are potentially achieved through alterations in the number, proportions, and properties of some lymphocyte subsets, with increased representation of regulatory T-cell (Treg) subsets, memory T- and B-lymphocytes, and transient effects on components of innate immunity (ie, neutrophils, macrophages, natural killer cells) (LEMTRADA Summary of Product Characteristics, 2016). This rebalancing of the immune system may contribute to the sustained efficacy of alemtuzumab without re-treatment (Bittner and Wiendl, 2016; Ruck et al., 2015; Turner et al., 2015).

Alemtuzumab is a highly effective therapy for relapsing remitting multiple sclerosis (RRMS). Alemtuzumab is indicated for treating adult patients with RRMS with active disease defined by clinical or imaging features based on phase 3 studies, in which treatment-naive patients (CARE-MS I; NCT00530348) or those with inadequate response to prior treatment (CARE-MS II; NCT00548405) showed significantly greater improvements in clinical and magnetic resonance imaging (MRI) outcomes, including brain volume loss (BVL), compared with those receiving subcutaneous interferon $\beta-1 \mathrm{a}$. (Cohen et al., 2012; Coles et al., 2012). Patients who participated in the core CARE-MS I and II trials could enroll in an extension study (NCT00930553), which demonstrated that alemtuzumab-treated patients experienced durable efficacy through 5 years (Coles et al., 2017b; Havrdova et al., 2017). Patients who completed the extension study could 
enroll in the 5-year TOPAZ study (NCT02255656) for further long-term evaluation (Coles et al., 2017a; Singer et al., 2017). In TOPAZ, 86\% (CARE-MS I) and 81\% (CARE-MS II) remained on study through Year 7, with 59\% (CARE-MS I) and 47\% (CARE-MS II) receiving only the initial two courses of alemtuzumab and no other treatments (Coles et al., 2017a; Singer et al., 2017). By Year 7, 74\% and 69\% of patients from CARE-MS I and II, respectively, were free of 6-month confirmed disability worsening (CDW), whereas $37 \%$ and $44 \%$ of patients from CARE-MS I and II, respectively, achieved 6-month confirmed disability improvement (CDI). Additionally, $78 \%$ and $73 \%$ of patients from CARE-MS I and II, respectively, demonstrated improved or stable disability, as measured by the expanded disability status scale (EDSS). Median yearly BVL remained low at Year 6 (CARE-MS I: $-0.17 \%$ and CARE-MS II: 0.10\%) (Ziemssen and Thomas, 2017). Most patients were free of MRI lesion activity (CARE-MS I: $68 \%$ and CARE MS II: 67\%) and achieved no evidence of disease activity in Year 7 (CARE-MS I: 61\% and CARE-MS II: 60\%) (Coles et al., 2017a; Singer et al., 2017).

Infusion-associated reactions (IARs) are the most frequently reported AEs in alemtuzumab-treated patients, affecting $\sim 90 \%$ of patients in clinical trials (Cohen et al., 2012; Coles et al., 2017b; Coles et al., 2012; Havrdova et al., 2017). Most IARs were mild-to-moderate in severity and generally decreased in number with each subsequent alemtuzumab treatment course. Incidence of treatment discontinuation due to IARs was low; IARs led to $1(0.03 \%)$ treatment discontinuation in CARE-MS I due to allergic dermatitis and $5(1.1 \%)$ discontinuations in CARE-MS II due to noncardiac chest pain and dyspnea in 1 patient, and pharyngeal edema, rash, purpura, and urticaria each in 1 
patient. The most common IARs included headache, rash, nausea, and pyrexia. These reactions may reflect cytokine release associated with alemtuzumab-induced lymphocyte lysis (Cohen et al., 2012; Coles et al., 2017b; Coles et al., 2012; Havrdova et al., 2017).

The primary objective of EMERALD was to assess the impact of a different medication algorithm on development and/or management of IARs in RRMS patients receiving two courses of alemtuzumab. 


\section{Materials and Methods}

\subsection{Patients}

Inclusion criteria were adult RRMS patients who initiated treatment with alemtuzumab according to the approved label in the country of treatment and who signed written informed consent. Patients were excluded if they previously received alemtuzumab, had any known contraindications to alemtuzumab according to labeling in the country of treatment, were participating in another investigational interventional study, had any known contraindications to symptomatic therapy used in infusionmanagement guidance based on their local approved label, were women of childbearing potential not using birth control and/or were unwilling or unable to be tested for pregnancy, pregnant (as defined as positive $\beta$-HCG blood test) or breastfeeding, had known infection with latent or active tuberculosis, or had known infection with hepatitis $B$ or $\mathrm{C}$ virus.

\subsection{Study Design}

EMERALD was a multicenter, multinational, single-arm, phase 4 , open-label study conducted at 19 sites in Belgium, France, the Netherlands, and Spain. EMERALD was a two-period study with mandatory administration of a comprehensive medication regimen aimed to prevent and/or manage alemtuzumab-associated IARs during the standard two-treatment course (Figure 1). Period 1 was defined from the first alemtuzumab dose to Day 0 of Period 2. During Period 1, patients began pre-infusion medications on Day 0 (the day before the first infusion). Period 2 was defined from the first alemtuzumab dose in Period 2 to end of study (Day 30 of Period 2). Infusion period was defined as the start of alemtuzumab dose through 24 hours after each infusion 
during Periods 1 and 2. The On-study Period was defined as the first alemtuzumab dose of Period 1 to end of study.

Figure 1.-Study Design. ${ }^{a}$ After the end of Period 2, patients were followed by their physician in a regular healthcare setting until the 48-month safety monitoring period is completed. Abbreviations: EOS, end of study; FU, follow-up; IAR, infusion-associated reaction; IV, intravenous; RRMS, relapsing remitting multiple sclerosis.

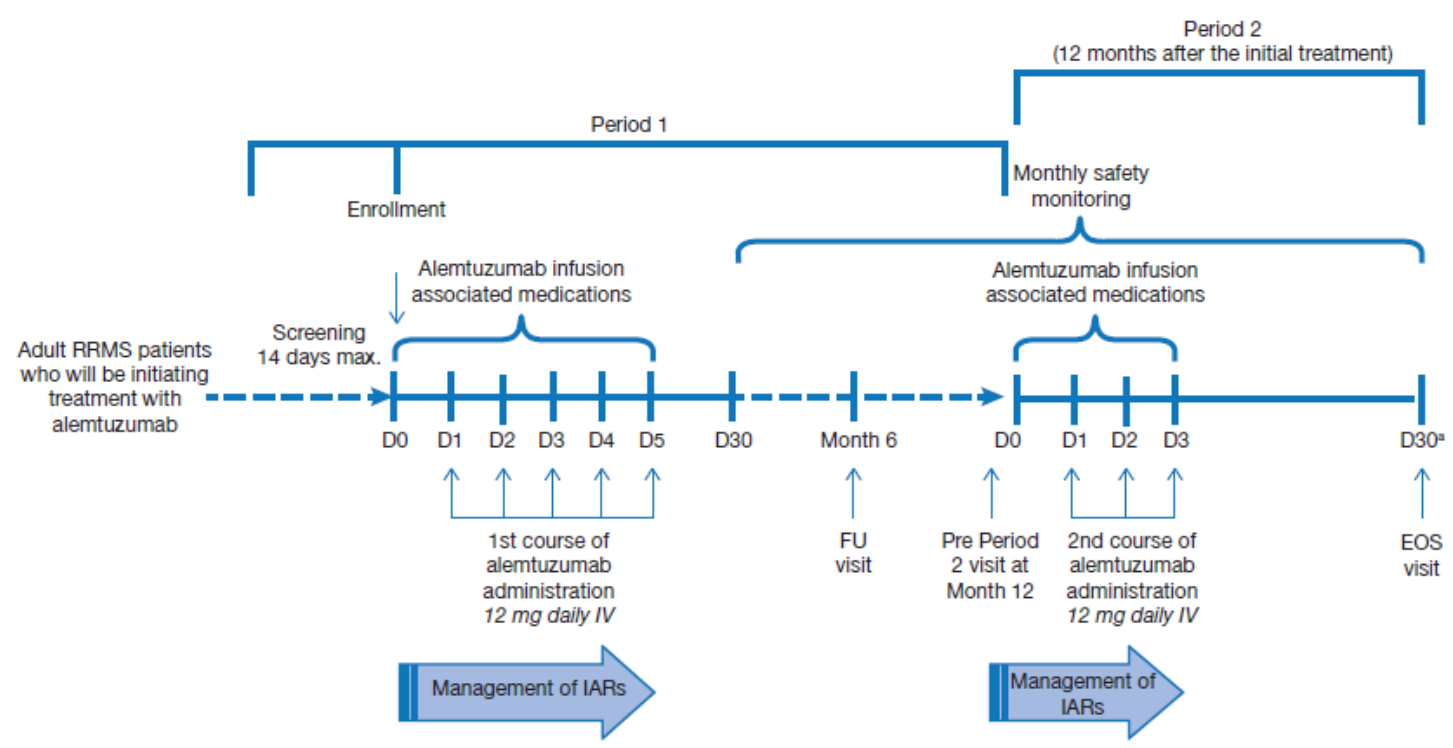

After a maximum of a 2-week screening, patients were enrolled. Patients began the pre-infusion regimen the day before starting the first alemtuzumab course, infusions of $12 \mathrm{mg} /$ day for 5 consecutive days (total dose of $60 \mathrm{mg}$ ), accompanied by the infusion-management medications. The second course was administered 12 months later, wherein patients received alemtuzumab infusions of $12 \mathrm{mg} /$ day for 3 consecutive 
days (total dose of $36 \mathrm{mg}$ ) with the same pre-infusion regimen and infusionmanagement medications. Guidance for administering the infusion-management medication algorithm is shown in Table 1. Patients underwent monthly safety monitoring throughout the study. 
Page 13

1 Table 1. Administration Algorithm of Mandatory and "As Needed" Associated Medication During EMERALD

\begin{tabular}{|c|c|c|c|c|}
\hline \multirow[b]{2}{*}{ Medication } & \multirow{2}{*}{$\begin{array}{c}\text { Day } 0 \\
\begin{array}{l}1 \text { day before } \\
\text { infusion }\end{array} \\
\end{array}$} & \multicolumn{3}{|c|}{ Days of alemtuzumab infusions } \\
\hline & & Pre-infusion ${ }^{b}$ & $\begin{array}{c}\text { During } \\
\text { infusion }\end{array}$ & $\begin{array}{c}\text { Post- } \\
\text { infusion }\end{array}$ \\
\hline $\begin{array}{l}\mathrm{H}_{1} \text { antagonist according to the local label (eg, cetirizine } 10 \mathrm{mg} \text { or } \\
\text { equivalent) in the afternoon }\end{array}$ & Mandatory & - & - & Mandatory \\
\hline $\mathrm{H}_{1}$ antagonist $25 \mathrm{mg}$ IV diphenhydramine or equivalent & - & Mandatory & $\begin{array}{l}\text { In case of } \\
\text { pruritus/rash }\end{array}$ & - \\
\hline $\begin{array}{l}\mathrm{H}_{2} \text { antagonist in the morning and afternoon or equivalent gastro- } \\
\text { protector medications prescribed according to the local label (ie, } \\
\text { proton pump inhibitors) }\end{array}$ & Mandatory & Mandatory & 1 & Mandatory \\
\hline $\begin{array}{l}\text { Methylprednisolone } 1,000 \mathrm{mg} \text { orally }\left(\text { Medrol }^{\circledR}\right)(10 \text { tablets of } 100 \mathrm{mg} \\
\text { each in the morning) }\end{array}$ & Mandatory & - & - & - \\
\hline $\begin{array}{l}\text { Methylprednisolone IV } 1,000 \mathrm{mg}(50 \% \text { dose reductions from Day } 3 \\
\text { [500 mg] to Day } 5 \text { [125 mg] in Period } 1 \text { and from Day } 1 \text { [750 mg] to } \\
\text { Day } 3 \text { [250 mg] in Period } 2)\end{array}$ & - & $\begin{array}{l}\text { Mandatory } \\
\text { following } \\
\text { immediately IV } \\
\text { diphenhydramine }\end{array}$ & - & As needed \\
\hline NSAID/antipyretic: 500 mg oral paracetamol or equivalent & - & Mandatory & $\begin{array}{c}\text { In case of } \\
\text { pain/headache }\end{array}$ & As needed \\
\hline Antiemetic but no phenothiazine (eg, ondansetron $8 \mathrm{mg}$ or equivalent) & - & - & $\begin{array}{l}\text { In case of } \\
\text { nausea }\end{array}$ & As needed \\
\hline Acyclovir $200 \mathrm{mg}$ orally or equivalent & - & Mandatory ${ }^{\dagger}$ & - & Mandatory ${ }^{\dagger}$ \\
\hline $0.9 \%$ sodium chloride (normal saline) bolus $\mathrm{IV}^{9}$ & - & - & $\begin{array}{l}\text { In case of } \\
\text { dehydration }\end{array}$ & - \\
\hline \multicolumn{5}{|c|}{$\begin{array}{l}\text { a } 1 \text { day before infusion patients took medications at home which were recorded in a patient diary. } \\
b 1 \text { hour prior to infusion. } \\
\text { c If IARs occurred during infusion, the patient may receive as needed. } \\
d \text { The evening of alemtuzumab infusion. } \\
{ }^{2} \text { Not to exceed maximum daily recommended dose according to the local label. } \\
{ }^{f} \text { Patients must continue to receive acyclovir } 200 \mathrm{mg} \mathrm{PO} B I D \text { or equivalent until Day } 30 \text { to minimize herpes virus infection. } \\
g^{g} \text { Fluid intake was encouraged and monitored. } \\
\text { Abbreviations: BID, twice daily; } \mathrm{H}_{1} \text {, histamine receptor } \mathrm{H}_{1} ; \mathrm{H}_{2} \text {, histamine receptor } \mathrm{H}_{2} \text {; IAR, infusion-associated reaction; IV, intravenous; NSAID, nonsteroidal anti- } \\
\text { inflammatory drug; } \mathrm{PO} \text {, orally. }\end{array}$} \\
\hline
\end{tabular}


The end-of-study visit was performed on Day 30 of Period 2. After study completion, patients were followed by their physician in a regular healthcare setting until the 48-month safety monitoring period was completed according to the Summary of Product Characteristics (SmPC) and Risk Management Plan (RMP).

Primary endpoints were proportion of patients with at least one IAR during the study period, overall and by severity grade, and distribution of IARs by severity grade. Serious adverse events (SAEs) were evaluated. Monitoring of potential autoimmune AEs according to the RMP for alemtuzumab included urinalysis with microscopy, complete blood count with differential, and serum creatinine before treatment initiation and monthly during the study; thyroid-stimulating hormone levels were tested before 11 treatment initiation and every 3 months.

\subsection{Treatments}

Alemtuzumab was administered by intravenous infusion over approximately 4 hours. If IARs were evident during the infusion, the individual investigators could prolong the infusion duration based on their clinical judgment. The infusionmanagement medication regimen was expanded upon recommendations informed by experts from the SmPC for treatment of active RRMS with alemtuzumab (European Medicines Agency) (Tables 1 and 2). For example, the SmPC states that patients should be pretreated with corticosteroids immediately before alemtuzumab administration for the first 3 days of each treatment course. During EMERALD, patients

21 received intravenous methylprednisolone on Day 0 and then every day before each 22 infusion for each treatment course of 5 and 3 days, respectively, in Period 1 and Period 2, and in the evenings post-infusion as needed. Pretreatment with antihistamines and/or 
antipyretics, suggested in the SmPC, was mandatory during EMERALD (cetirizine [10 mg orally], diphenhydramine [25 mg intravenously], gastroprotection [proton pump inhibitors] according to the local label, and paracetamol [500 mg orally]). Oral prophylaxis for herpes infection is also recommended by the SmPC for all patients starting the first day of each treatment course and continuing for a minimum of 1 month following alemtuzumab treatment. Patients in EMERALD received acyclovir (200 mg orally) twice daily beginning the first day of each alemtuzumab course and continuing for 30 days following completion of each course. Additional agents not mentioned in the SmPC, but given as needed during EMERALD, included antiemetics and normal saline (Table 1).

Table 2. Mandatory and "As Needed" Associated Medications for CARE-MS I and II and Guidelines from the SmPC for the Treatment of Active RRMS with Alemtuzumab

\begin{tabular}{|l|l|l|}
\hline Treatment & \multicolumn{1}{|c|}{ CARE-MS I and II } & \multicolumn{1}{|c|}{ SmPC Guidelines $^{\text {a }}$} \\
\hline $\begin{array}{l}\text { Antipyretics } \\
\text { Antihistamines }\end{array}$ & $\begin{array}{l}\text { Permitted at the Investigator's } \\
\text { discretion to minimize IARs known to } \\
\text { be associated with alemtuzumab } \\
\text { administration (eg, rash) }\end{array}$ & $\begin{array}{l}\text { Pretreatment with antihistamines } \\
\text { and/or antipyretics may } \\
\text { be considered }\end{array}$ \\
\hline $\begin{array}{l}\mathrm{H}_{2} \text { receptor blockers } \\
\text { Antiemetics }\end{array}$ & $\begin{array}{l}\text { Permitted at the Investigator's } \\
\text { discretion to minimize IARs known to } \\
\text { be associated with alemtuzumab } \\
\text { administration (eg, rash) }\end{array}$ & \\
\hline Methylprednisolone & $\begin{array}{l}\text { As prophylaxis of IARs administered } \\
\text { to all patients. All patients in both } \\
\text { treatment groups received 1 g/day of } \\
\text { IV methylprednisolone for 3 } \\
\text { consecutive days at Month 0 and } \\
\text { Month 12 }\end{array}$ & $\begin{array}{l}\text { Patients should be pretreated with } \\
\text { corticosteroids immediately prior to } \\
\text { alemtuzumab administration on } \\
\text { each of the first 3 days of any } \\
\text { treatment course }\end{array}$ \\
& $\begin{array}{l}\text { The dose of methylprednisolone could } \\
\text { be reduced at the investigator's } \\
\text { discretion for patients who did not } \\
\text { tolerate the standard regimen }\end{array}$ & \\
\hline
\end{tabular}




\begin{tabular}{|l|l|l|}
\hline Acyclovir & $\begin{array}{l}\text { Acyclovir } 200 \mathrm{mg} \text { twice daily or } \\
\text { equivalent, initiated during the trials, } \\
\text { was administered to all alemtuzumab } \\
\text { patients beginning on the first day of } \\
\text { each alemtuzumab course and } \\
\text { continuing for } 28 \text { days after the last } \\
\text { day }\end{array}$ & $\begin{array}{l}\text { Oral prophylaxis for herpes } \\
\text { infection should be administered to } \\
\text { all patients starting on the first day } \\
\text { of each treatment course and } \\
\text { continuing for a minimum of 1 } \\
\text { month following treatment with } \\
\text { alemtuzumab }\end{array}$ \\
\hline $\begin{array}{l}{ }^{a} \text { As published by the European Medicines Agency. } \\
\text { b If a patient assigned to the IFN } \beta-1 \mathrm{a} \text { arm had received corticosteroids for symptomatic treatment of a relapse } \\
\text { within 1 month (30 days) of a scheduled steroid infusion, that infusion was omitted. } \\
\text { Abbreviations: } \mathrm{H}_{2} \text {, histamine receptor } \mathrm{H}_{2} ; \text { IAR, infusion-associated reaction; RRMS, relapsing-remitting multiple } \\
\text { sclerosis; SmPC, Summary of Product Characteristics. }\end{array}$ \\
\hline
\end{tabular}

Patients in CARE-MS I and II received pretreatment with systemic steroids during each treatment course ( $1 \mathrm{~g} /$ day intravenous methylprednisolone on the first 3 days), and patients with IARs were treated symptomatically with concomitant antipyretics, antihistamines, and antiemetics at treating neurologist's discretion (Table 2). In contrast, the EMERALD protocol included a more comprehensive pretreatment regimen with mandatory antipyretics and analgesics, and $\mathrm{H}_{1}$ and $\mathrm{H}_{2}$ receptor antagonists. As mentioned previously, the EMERALD protocol required additional oral methylprednisolone administration 1 day before the first infusion, and intravenous methylprednisolone after each treatment course as needed (Table 1). Acyclovir was administered both before and after alemtuzumab infusion for prophylaxis against herpes infection as recommended by the SmPC.

\subsection{Safety Analysis}

The following safety populations were defined and used for endpoint reporting. The full safety set (SS) was defined as enrolled patients who received at least part of an alemtuzumab dose during Periods 1 or 2 . The first SS (Course 1) was defined as patients who received at least part of an alemtuzumab dose during Period 1 . The second SS (Course 2) was defined as patients from Course 1 who received at least part 
of an alemtuzumab dose during Period 2.

IAR data are discussed for EMERALD alone, and in comparison with patients who received alemtuzumab $12 \mathrm{mg}$ in the CARE-MS I and II studies.

\subsection{AE Definitions}

$A E$ and IAR definitions were based on standard designations. An IAR was defined as any $A E$ occurring during or within 24 hours of alemtuzumab infusion. $A n A E$ was defined as any untoward medical occurrence in a patient that may or may not have a causal relationship with alemtuzumab. Recording of AEs began from signed informed consent through end of study. An AE was considered serious (SAE) if it either resulted in death, was life-threatening, required hospitalization, resulted in disability/incapacity, was a congenital anomaly/birth defect, or was medically important. Adverse events of special interest (AESIs) were AEs (serious or nonserious) of scientific or medical concern specific to this treatment, which required ongoing monitoring, such as autoimmune cytopenias and other autoimmune disorders, infections, malignancy, hypersensitivity, or anaphylaxis.

Treatment-emergent adverse events (TEAEs) were any AEs occurring between first dose (Period 1) and end of study. Infusion-associated reactions were any TEAEs occurring during or within 24 hours after each infusion for both infusion periods, and were described for each 2-hour interval. IAR definition and severity grade ratings were consistent with previous clinical trials and described accordingly.

\subsection{Ethics}

The protocol was approved by the appropriate Independent Ethics Committees/Institutional Review Boards and complied with International Conference on 
1 Harmonisation guidelines for Good Clinical Practice (GCP). All patients provided written 2 informed consent prior to screening. The Sponsor conducted training sessions for 3 clinical research associates and held individual site initiation meetings to develop a 4 common understanding of the clinical study protocol, case report form, and study 5 procedures, in compliance with GCP. Monitoring of all investigative sites in Belgium, 6 France, Netherlands, and Spain was performed by the Sponsor's staff according to the 7 Sponsor's procedures. EMERALD is registered at ClinicalTrials.gov (NCT02205489). 8 
$13 . \quad$ Results

\section{$2 \quad 3.1 \quad$ Patient Characteristics}

Demographics, disease characteristics, and disease activity at baseline are

4 shown in Table 3. Most patients (91.4\%) had received treatment for MS prior to

5 EMERALD, the most common of which were natalizumab (32 patients; $55.2 \%$ ) and

6 fingolimod (31 patients; 53.4\%) (Table 3). Among the 31 patients who received

7 fingolimod, $18(58.1 \%)$ discontinued this treatment $<4$ months prior to alemtuzumab

8 initiation. Median duration between discontinuation of fingolimod and initiation of

9 alemtuzumab was 2.4 months. Of note, total white blood cell and lymphocyte counts

were consistent between patients who had received different types of prior diseasemodifying therapies (DMTs). During Periods 1 and 2, all patients received medication for concomitant conditions; the most common drug classes were nervous system drugs (98.3\% in Period 1 and $98.1 \%$ in Period 2, mainly analgesics and psycholeptics) and respiratory system drugs $(72.4 \%$ in Period 1 and $72.2 \%$ in Period 2, mainly antihistamines).

Table 3. Demographics, Disease Characteristics, and Clinical and MRI Data at Baseline

\begin{tabular}{|l|c|}
\hline & Total $(\mathbf{n}=\mathbf{5 8})$ \\
\hline Female, $\mathrm{n}(\%)$ & $35(60.3)$ \\
\hline Age, $\mathrm{y}$ & $36.4 \pm 8.1$ \\
\hline Clinical signs of disease activity at enrollment, $\mathrm{n}(\%)$ & $34 / 57(59.6)$ \\
\hline MRI signs of disease activity, $\mathrm{n}(\%)$ & $41(70.7)$ \\
\hline Clinical and MRI signs of disease activity, $\mathrm{n}(\%)$ & $29(50.0)$ \\
\hline EDSS score & $4.1 \pm 1.6$ \\
\hline Years since diagnosis ${ }^{a}$ & $8.0 \pm 6.3$ \\
\hline Relapses in the past year & $1.8 \pm 1.1$ \\
\hline Median time since last relapse, months & 2.1 \\
\hline Any prior MS therapy, $\mathrm{n}(\%)$ & $53(91.4)$ \\
\hline
\end{tabular}




\begin{tabular}{|c|c|}
\hline Antineoplastic and immunomodulating agents ${ }^{\mathrm{c}, \mathrm{d}}, \mathrm{n}(\%)$ & $51(87.9)$ \\
\hline Natalizumab (Tysabri ${ }^{\circledR}$ ) & $32(55.2)$ \\
\hline Fingolimod (Gilenya ${ }^{\circledR}$ ) & $31(53.4)$ \\
\hline Glatiramer acetate (Copaxone ${ }^{\circledR}$ ) & $23(39.7)$ \\
\hline Interferon beta-1a (Avonex $\left.{ }^{\circledR}\right)$ & $20(34.5)$ \\
\hline Interferon beta-1a (Rebif $\left.{ }^{\circledR}\right)$ & $18(31.0)$ \\
\hline \multicolumn{2}{|c|}{$\begin{array}{l}\text { a Years since diagnosis }=\text { (date of informed consent - date of diagnosis of multiple sclerosis }+1 / 365.25 . \\
{ }^{b} \mathrm{~N}=33(56.8 \%) \text { had at least } 2 \text { relapse episodes in the past year. } \\
{ }^{c} \text { Patients without prior antineoplastic and/or immunomodulating therapy received prior nervous system drug } \\
\text { systemic corticosteroids, or an investigational drug. } \\
{ }^{d} \text { Not comprehensive; prior antineoplastic and immunomodulating agents } \leq 13.8 \% \text { not listed. } \\
\text { Data are mean } \pm \mathrm{SD} \text { unless stated otherwise. } \\
\text { Data are comparable between Course } 1 \text { and Course } 2 . \\
\text { Abbreviations: EDSS, Expanded Disability Status Scale; MRI, magnetic resonance imaging; MS, multiple } \\
\text { sclerosis; SD, standard deviation. }\end{array}$} \\
\hline
\end{tabular}

Of the 61 patients screened, $58(95.1 \%)$ were enrolled into the study. Of the 58 patients who received the first infusion of Period 1, 57 (98.3\%) completed the 5 days of

Course 1. Fifty-four patients received the first infusion of Period 2 and 53 completed the 3-day course. All patients $(n=58)$ completed the Month 6 visit and 54 the Month 12 visit.

\subsection{Infusion-Associated Reactions}

A summary of IARs by severity grade for the On-study Period is presented in Table 4. IARs occurred in $91.4 \%(n=53)$ and $81.5 \%(n=44)$ of patients in Course 1 and Course 2, respectively. Types and overall incidence of IARs were similar to those reported previously for alemtuzumab in controlled clinical trials (Table 5). The three most common IARs were headache, pyrexia, and rash (Table 5). Headache was the most common IAR in EMERALD and occurred in $48.3 \%$ and $40.7 \%$ of patients in Course 1 and Course 2, respectively. Incidence of rash was reduced in EMERALD compared with CARE-MS I and II. Incidence of pyrexia in EMERALD was higher than in CARE-MS I and II. Insomnia was increased in EMERALD compared with CARE-MS I and II (Table 5). 
2 Table 4. Summary of IARs for On-Study Periods 1 and 2

\begin{tabular}{|c|c|c|c|}
\hline & SS (n = 58) & Course 1 (n = 58) & Course 2 (n = 54) \\
\hline $\begin{array}{l}\text { IAR within 24 hours } \\
\text { of any infusion }\end{array}$ & $54(93.1 \%)$ & $53(91.4 \%)$ & $44(81.5 \%)$ \\
\hline Grade 1: Mild & $51(87.9 \%)$ & $47(81.0 \%)$ & $34(63.0 \%)$ \\
\hline Grade 2: Moderate & $36(62.1 \%)$ & $32(55.2 \%)$ & $19(35.2 \%)$ \\
\hline Grade 3: Severe & $6(10.3 \%)$ & $6(10.3 \%)$ & $0(0.0 \%)$ \\
\hline $\begin{array}{l}\text { Serious IAR within } \\
\text { in hours of any }\end{array}$ & $9(15.5 \%)$ & $7(12.1 \%)$ & $2(3.7 \%)$ \\
\hline Grade 1: Mild & $4(6.9 \%)$ & $4(6.9 \%)$ & $0(0.0 \%)$ \\
\hline Grade 2: Moderate & $4(6.9 \%)$ & $2(3.4 \%)$ & $2(3.7 \%)$ \\
\hline Grade 3: Severe & $2(3.4 \%)$ & $2(3.4 \%)$ & $0(0.0 \%)$ \\
\hline $\begin{array}{l}\text { Patients may have experienced IARs on multiple occasions whereby each IAR was recorded. } \\
\text { Abbreviations: SS, safety set; IAR, infusion-associated reaction. }\end{array}$ & \\
\hline
\end{tabular}

4 Table 5. Infusion-Associated Reactions (IARs) Occurring in $\geq 5 \%$ of Patients for Periods 1 5 and 2 of the EMERALD Study, and for Course 1 and 2 of the CARE-MS I and CARE-MS II

\section{Studies}

\begin{tabular}{|l|c|c|c|c|}
\hline & $\begin{array}{c}\text { EMERALD } \\
\text { Course 1 }\end{array}$ & $\begin{array}{c}\text { EMERALD } \\
\text { Course 2 }\end{array}$ & $\begin{array}{c}\text { CARE MS-I } \\
\text { and II } \\
\text { Course 1 }\end{array}$ & $\begin{array}{c}\text { CARE MS-I } \\
\text { and II } \\
\text { Course 2 }\end{array}$ \\
\cline { 2 - 5 } Preferred term n (\%) & $\begin{array}{c}\mathbf{1 2} \mathbf{~ m g} \\
\mathbf{( n = 5 8 )}\end{array}$ & $\begin{array}{c}\mathbf{1 2} \mathbf{~ m g} \\
\mathbf{( n = 5 4 )}\end{array}$ & $\begin{array}{c}\mathbf{1 2} \mathbf{~ m g} \\
\mathbf{( n = 8 1 1 )}\end{array}$ & $\begin{array}{c}\mathbf{1 2} \mathbf{~ m g} \\
(\mathbf{n}=\mathbf{7 9 1})\end{array}$ \\
\hline Any class & $\mathbf{5 3 ( 9 1 . 4 )}$ & $\mathbf{4 4 ( 8 1 . 5 )}$ & $\mathbf{6 8 7}(\mathbf{8 4 . 7})$ & $\mathbf{5 4 3 ( 6 8 . 6 )}$ \\
\hline Headache & $28(48.3)$ & $22(40.7)$ & $289(35.6)$ & $221(27.9)$ \\
\hline Pyrexia & $14(24.1)$ & $8(14.8)$ & $124(15.3)$ & $104(13.1)$ \\
\hline Rash & $10(17.2)$ & $3(5.6)$ & $294(36.3)$ & $112(14.2)$ \\
\hline Bradycardia & $9(15.5)$ & $3(5.6)$ & $24(3.0)$ & $6(0.8)$ \\
\hline Insomnia & $9(15.5)$ & - & $56(6.9)$ & - \\
\hline Erythema & $8(13.8)$ & - & $28(3.5)$ & - \\
\hline
\end{tabular}




\begin{tabular}{|l|c|c|c|c|}
\hline Nausea & $8(13.8)$ & $3(5.6)$ & $91(11.2)$ & $57(7.2)$ \\
\hline Pruritus & $8(13.8)$ & $5(9.3)$ & $72(8.9)$ & $20(2.5)$ \\
\hline Abdominal pain upper & $6(10.3)$ & $3(5.6)$ & $11(1.4)$ & $8(1.0)$ \\
\hline Fatigue & $6(10.3)$ & - & $46(5.7)$ & - \\
\hline Urticaria & $6(10.3)$ & - & $95(11.7)$ & - \\
\hline Abdominal pain & $4(6.9)$ & - & $8(1.0)$ & - \\
\hline Chest discomfort & $4(6.9)$ & - & $40(4.9)$ & - \\
\hline Diarrhea & $4(6.9)$ & - & $15(1.8)$ & - \\
\hline Dyspnea & $4(6.9)$ & - & $43(5.3)$ & - \\
\hline Flushing & $4(6.9)$ & - & $58(7.2)$ & - \\
\hline Constipation & $3(5.2)$ & - & $6(0.7)$ & - \\
\hline Hot flush & $3(5.2)$ & $3(5.6)$ & $9(1.1)$ & $2(0.3)$ \\
\hline Musculoskeletal stiffness & $3(5.2)$ & - & $3(0.4)$ & - \\
\hline Presyncope & $3(5.2)$ & - & $1(0.1)$ & - \\
\hline Pruritus generalized & $3(5.2)$ & - & $6(0.7)$ & - \\
\hline Note: Dash represents IARs that appeared in <5\% of patients. \\
A patient can be counted in several categories of preferred term by system organ class.
\end{tabular}

1

Most IARs occurred within 6 hours of initiating alemtuzumab infusion, with a peak during the first 2 hours (Table 6). Nearly all IARs decreased in rate from Course 1 to Course 2 ; incidence was $48.3 \%$ and $40.7 \%$ for headache, $24.1 \%$ and $14.8 \%$ for pyrexia, $17.2 \%$ and $5.6 \%$ for rash, and $15.5 \%$ and $5.6 \%$ for bradycardia, respectively. Hot flush was the only IAR that did not decrease in incidence from Course 1 to Course 2 (5.2\% and $5.6 \%$, respectively).

Table 6. Number of Patients With Infusion-Associated Reactions (IARs) by 2-Hour Interval and by Grade According to Time From Start of Infusion

\begin{tabular}{|l|c|c|c|}
\hline $\begin{array}{l}\text { Period 1 } \\
\text { Total n= 58 }\end{array}$ & Grade 1 & Grade 2 & Grade 3 \\
\hline $0-2 \mathrm{~h}$ & 30 & 14 & 5 \\
\hline $2-4 \mathrm{~h}$ & 9 & 10 & 1 \\
\hline $4-6 \mathrm{~h}$ & 18 & 8 & 0 \\
\hline $6-8 \mathrm{~h}$ & 7 & 3 & 0 \\
\hline $8-10 \mathrm{~h}$ & 7 & 1 & 0 \\
\hline $10-12 \mathrm{~h}$ & 9 & 4 & 1 \\
\hline $12-14 \mathrm{~h}$ & 7 & 6 & 1 \\
\hline
\end{tabular}




\begin{tabular}{|l|c|c|c|}
\hline $\begin{array}{l}\text { Period 1 } \\
\text { Total } \mathbf{n}=\mathbf{5 8}\end{array}$ & Grade 1 & Grade 2 & Grade 3 \\
\hline $14-16 \mathrm{~h}$ & 7 & 1 & 0 \\
\hline $16-18 \mathrm{~h}$ & 2 & 2 & 0 \\
\hline $18-20 \mathrm{~h}$ & 5 & 0 & 0 \\
\hline $20-22 \mathrm{~h}$ & 5 & 1 & 1 \\
\hline $22-24 \mathrm{~h}$ & 4 & 3 & 0 \\
\hline $24-26 \mathrm{~h}$ & 3 & 2 & 0 \\
\hline $\begin{array}{l}\text { Period 2 } \\
\text { Total } \mathbf{n}=\mathbf{5 4}\end{array}$ & Grade 1 & Grade 2 & Grade 3 \\
\hline $0-2 \mathrm{~h}$ & 15 & 10 & 0 \\
\hline $2-4 \mathrm{~h}$ & 8 & 4 & 0 \\
\hline $4-6 \mathrm{~h}$ & 11 & 2 & 0 \\
\hline $6-8 \mathrm{~h}$ & 4 & 1 & 0 \\
\hline $8-10 \mathrm{~h}$ & 2 & 3 & 0 \\
\hline $10-12 \mathrm{~h}$ & 1 & 1 & 0 \\
\hline $12-14 \mathrm{~h}$ & 6 & 2 & 0 \\
\hline $14-16 \mathrm{~h}$ & 4 & 0 & 0 \\
\hline $16-18 \mathrm{~h}$ & 1 & 0 & 0 \\
\hline $18-20 \mathrm{~h}$ & 2 & 1 & 0 \\
\hline $20-22 \mathrm{~h}$ & 2 & 1 & 0 \\
\hline $22-24 \mathrm{~h}$ & 2 & 3 & 0 \\
\hline $24-26 \mathrm{~h}$ & 1 & 0 & 0 \\
\hline
\end{tabular}

Serious IARs occurred in $15.5 \%(n=9)$ of patients who received alemtuzumab

3 (most occurred during the first course) (Table 7). This is a higher rate than reported in

4 clinical trials of alemtuzumab. Serious IARs occurred in $3 \%(n=12)$ of patients in each CARE-MS I and II. In EMERALD, the most common serious IARs were cardiac disorders, with bradycardia occurring in 3 patients and tachycardia in 1 patient. All other

7 serious IARs occurred in $\leq 1$ patient. Bradycardia led to permanent withdrawal of 8 alemtuzumab for 1 patient. Bradycardia and tachycardia were each experienced as

9 serious IARs by 1 patient in CARE-MS I. Bradycardia and tachycardia were not reported as serious IARs in any patient who received alemtuzumab $12 \mathrm{mg}$ in CARE-MS II or in

11 the phase 2 trial (CAMMS223) (Coles et al., 2008; Coles et al., 2012). No IAR led to 12 death in EMERALD, CAMMS223, or CARE-MS I or II. 
1 Table 7. Summary of Serious Infusion-Associated Reactions (IARs) by Frequency for On-

2 Study Period

\begin{tabular}{|c|c|}
\hline $\begin{array}{l}\text { MedDRA System Organ Class Name and Preferred } \\
\text { Term Name }\end{array}$ & $\begin{array}{c}\text { Total } \mathbf{n}=\mathbf{5 8} \\
\mathbf{n}(\%)\end{array}$ \\
\hline At least one serious IAR & $9(15.5)$ \\
\hline Cardiac & $4(6.9)$ \\
\hline Bradycardia & $3(5.2)$ \\
\hline Tachycardia & $1(1.7)$ \\
\hline General and administration site reactions & $2(3.4)$ \\
\hline Hyperthermia & $1(1.7)$ \\
\hline Pyrexia & $1(1.7)$ \\
\hline Investigations & $2(3.4)$ \\
\hline Fibrin D dimer increased & $1(1.7)$ \\
\hline Gamma-glutamyl transferase increased & $1(1.7)$ \\
\hline Skin and subcutaneous tissue & $2(3.4)$ \\
\hline Erythema & $1(1.7)$ \\
\hline Urticaria & $1(1.7)$ \\
\hline Hepatobiliary & $1(1.7)$ \\
\hline Hepatocellular injury & $1(1.7)$ \\
\hline Immune system & $(1.7)$ \\
\hline Hypersensitivity & system organ class. \\
\hline Note: A patient can be counted in several categories of preferred term by
\end{tabular}

Incidence of infections in EMERALD was similar to that reported previously in 
1 On-study Period were upper respiratory tract infections $(n=28 ; 48.3 \%)$, lower respiratory

2 tract and lung infections $(n=9 ; 15.5 \%)$, urinary tract infections $(n=13 ; 22.4 \%)$, and

3 herpes infections $(n=9 ; 15.5 \%)$. Of the 9 patients who experienced herpes infections ( 3

4 cases of herpes zoster and 6 cases of oral herpes), 7 were considered to be treatment-

5 related, with 4 cases $(57.1 \%)$ occurring more than 1 month after Period 1 and acyclovir

6 treatment, 1 case occurring before study treatment, 1 case occurring during treatment

7 with acyclovir, and 1 case occurring in the time between Period 1 and 2. Incidences of

8 infection in CARE-MS I and II were the following: upper respiratory tract infections (15\%

9 and $16 \%)$; lower respiratory tract infections (8.2\% and $9.7 \%)$; urinary tract infections

10 (17\% and $21 \%$ ); and herpes infections (16\% and 16\%), respectively (Cohen et al.,

11 2012; Coles et al., 2012). No infections led to death in EMERALD, CAMMS223, or

12 CARE-MS I and II.

13 Adverse events of special interest are shown in Table 8. The majority of AESls 14 occurred during Course 1 (8 of 9; 1 viral hepatitis occurred during Course 2). One case 15 of immune thrombocytopenic purpura and 3 cases of hyperthyroidism disorder (2 16 Basedow's disease, 1 hyperthyroidism) were reported during the study period, all of 17 which were resolved by study end. Two patients (3.4\%) had 1 TEAE leading to 18 permanent treatment discontinuation (bradycardia for 1 patient and viral hepatitis for 1 19 patient). Herpes zoster, an AESI, occurred in 1 (1.7\%) patient.

21 Table 8. Adverse Events (AEs) of Special Interest for On-Study Period

\begin{tabular}{|l|c|}
\hline $\begin{array}{l}\text { MedDRA System Organ Class Name and Preferred Term } \\
\text { Name }\end{array}$ & $\begin{array}{c}\text { Total } \mathbf{n}=\mathbf{5 8} \\
\mathbf{n}(\%)\end{array}$ \\
\hline Any class & $9(15.5)$ \\
\hline
\end{tabular}




\begin{tabular}{|l|c|}
\hline $\begin{array}{l}\text { MedDRA System Organ Class Name and Preferred Term } \\
\text { Name }\end{array}$ & $\begin{array}{c}\text { Total } \mathbf{n}=\mathbf{5 8} \\
\mathbf{n}(\%)\end{array}$ \\
\hline Endocrine & $3(5.2)$ \\
\hline Basedow's disease & $2(3.4)$ \\
\hline Hyperthyroidism & $1(1.7)$ \\
\hline Infections and infestations ${ }^{\text {a }}$ & $3(5.2)$ \\
\hline Herpes zoster & $1(1.7)$ \\
\hline Hepatitis viral & $1(1.7)$ \\
\hline Vulvovaginal candidiasis & $1(1.7)$ \\
\hline Blood and lymphatic system & $1(1.7)$ \\
\hline Immune thrombocytopenic purpura & $1(1.7)$ \\
\hline Hepatobiliary & $1(1.7)$ \\
\hline Hepatocellular injury & $1(1.7)$ \\
\hline $\begin{array}{l}\text { Investigations } \\
\text { Human papilloma virus test positive }\end{array}$ & $1(1.7)$ \\
\hline $\begin{array}{l}{ }^{2} \text { Other infections not reported as AEs of special interest are considered TEAEs. } \\
\text { Note: A patient can be counted in several categories of preferred term by system organ class. }\end{array}$ \\
\hline
\end{tabular}




\section{Discussion}

As with most monoclonal antibodies, IARs are frequently reported AEs associated with alemtuzumab treatment (Caon et al., 2015). The observation that most IARs in EMERALD were mild or moderate and decreased in rate during subsequent infusions is consistent with previous studies and with patient response to other monoclonal antibodies (Lenz, 2007). Consistent with previous controlled clinical trials, no deaths occurred in this study.

EMERALD evaluated use of a comprehensive medication regimen that was developed to prevent and manage IARs during alemtuzumab infusion in a real-world population. However, small sample size, lack of a comparator arm, and differences in population between EMERALD and CARE-MS I and II limit data interpretation. For example, more than half of patients in EMERALD were treated previously with natalizumab, as is common in the real-world population (Berger et al., 2017). In comparison with patients in CARE-MS I and II, patients in EMERALD presented with more comorbidities, were older, had longer disease duration, and had been treated with a greater number of prior MS treatments including immunomodulating therapy. These differences in patient populations may have altered risk of IARs and reduced the feasibility of cross-trial comparison. Furthermore, potential differences in alemtuzumab infusion rates further confounded study assessment, as clinicians may slow infusions to manage IARs (Caon et al., 2015).

Despite EMERALD's limitations, IAR types and overall incidence were comparable with those reported in CARE-MS I and II. The only IARs with a substantial difference (two-fold) between Course 1 of EMERALD and CARE-MS I and II were rash 
1 (17.2\% [EMERALD] vs. 36.3\% [CARE-MS I and II]) and insomnia (15.5\% [EMERALD]

2 vs. $6.9 \%$ [CARE-MS I and II] and 7.6\% [CARE-MS II]). It is possible that differences in 3 treatment with methylprednisolone in this study compared with CARE-MS I and II may 4 have contributed to the decreased rash and the increased insomnia. Compared with 5 CARE-MS I and II, patients in EMERALD received additional pretreatment with 6 methylprednisolone 1 day before infusion, as well as post-infusion as needed. Nausea, 7 infections, and other IARs associated with intravenous methylprednisolone (Le Page et 8 al., 2015) did not increase during EMERALD, suggesting that methylprednisolone's 9 effect was most apparent in the reduced incidence of rash. It is possible that insomnia associated with prophylaxis may be more easily tolerated by patients than rash.

11 Prophylaxis shown to reduce rash in alemtuzumab-treated patients may be beneficial in these cases.

A higher rate of bradycardia and serious IARs was observed in EMERALD compared with previous trials. Differences in baseline characteristics, such as increased comorbidities, may have contributed to increases in cardiac events among EMERALD patients. An additional comparison of IAR frequency between EMERALD patients with prior DMT use and CARE-MS II patients, all of whom also had prior DMT use, showed increased rates of bradycardia and palpitations for patients in EMERALD. This suggests that factors other than prior DMT use (eg, comorbidities) may increase the risk of cardiac-related IARs after alemtuzumab. In EMERALD, 3 of the 9 patients with brachycardia had history of endocrine, cardiac, and metabolic disorders. Furthermore, 2 of these 3 patients had history of bradycardia prior to the study. 
Additionally, most patients in EMERALD were hospitalized during the entire duration of infusion so they could be closely monitored, which was not required by EMERALD's protocol and may have increased the rate of reported AEs. Twenty-fourhour hospitalization during infusion periods was not part of the protocol in CARE-MS I and II. The in-hospital monitoring of patients in EMERALD, including heart rate, may have facilitated identification of transient heart rate alterations contributing to the higher $A E$ rates observed for these events. The increase in reported incidence of pyrexia, although not a two-fold increase, in EMERALD versus CARE-MS I and II may be associated with the increased frequency of patient temperature measurements during hospitalization in EMERALD, wherein temperature measurements were recorded approximately at 1 hour pre-infusion, hourly during infusion, and 1 hour and 2 hour postinfusion.

Pharmacologic intervention for IAR management in previous clinical trials included a variety of doses and schedules, which were largely dictated by individual patient need and physician choice (Caon et al., 2015). Thus, the effectiveness of IAR prophylaxis had been unclear. The EMERALD treatment regimen is generally aligned with recommendations from clinical trial experience and labeling; the key difference is the consistent application of a specific medication algorithm developed from consensus group recommendations that included increased corticosteroid dosing, and mandatory administration of antihistamines, antipyretics, and $\mathrm{H}_{1} / \mathrm{H}_{2}$ receptor antagonists. (Berger et al., 2017; Caon et al., 2015; McEwan et al., 2016) However, based on the overall findings in this study, there is no compelling advantage to adopt the IAR management 
1 setting should follow the recommendations in labeling and, as is the case in clinical 2 practice, should be left to physician discretion on an individual patient basis. 


\section{Conclusion}

In this phase 4 study, we assessed distribution of IARs by severity grade when

3 alemtuzumab is administered to RRMS patients in the real world with a specified

4 medication algorithm aimed at preventing and managing IARs. Inclusion of real-world

5 patients in EMERALD provides an understanding of the AEs physicians will likely

6 encounter with alemtuzumab treatment. It is reassuring that no previously unknown or

7 unexpected SAEs or TEAEs of special interest were reported during this study. We

8 found that types and overall incidence of IARs were generally consistent with previous

9 controlled clinical trials. However, incidence of rash was reduced in this study compared

10 with the previous trials, which may have been associated with this study's prophylaxis

11 treatment regimen. The increased incidence of serious IARs (eg, cardiac events)

12 potentially reflected differences in baseline characteristics in this population. 
ACKNOWLEDGMENTS

2

3 Financial support for medical editorial assistance was provided by Sanofi. We thank

4 Sarah Jablonski Schandle, PhD, ProEd Communications, Inc., for her medical editorial

5 assistance with this manuscript. This manuscript was reviewed by Darren P. Baker, $6 \mathrm{PhD}$, Erika Bueno, PhD, and Colin Mitchell, PhD, of Sanofi.

7 


\section{REFERENCES}

LEMTRADA Summary of Product Characteristics, 2016. ema/europa.edu (2016). LEMTRADA - Summary of Product Characteristics (SPC) - [online] Available at: http://www.ema.europa.eu/ema/index.jsp?curl=pages/medicines/human/medicine s/003718/human_med_001678.jsp\&mid=WC0b01ac058001d124 [Accessed 19 Oct. 2017].

Berger, T., Elovaara, I., Fredrikson, S., McGuigan, C., Moiola, L., Myhr, K.M., OrejaGuevara, C., Stoliarov, I., Zettl, U.K., 2017. Alemtuzumab Use in Clinical Practice: Recommendations from European Multiple Sclerosis Experts. CNS Drugs 31(1), 33-50.

Bittner, S., Wiendl, H., 2016. Neuroimmunotherapies Targeting T Cells: From Pathophysiology to Therapeutic Applications. Neurotherapeutics 13(1), 4-19.

Caon, C., Namey, M., Meyer, C., Mayer, L., Oyuela, P., Margolin, D.H., Rizzo, M., 2015. Prevention and Management of Infusion-Associated Reactions in the Comparison of Alemtuzumab and Rebif((R)) Efficacy in Multiple Sclerosis (CARE-MS) Program. Int J MS Care 17(4), 191-198.

Cohen, J.A., Coles, A.J., Arnold, D.L., Confavreux, C., Fox, E.J., Hartung, H.P., Havrdova, E., Selmaj, K.W., Weiner, H.L., Fisher, E., Brinar, V.V., Giovannoni, G., Stojanovic, M., Ertik, B.I., Lake, S.L., Margolin, D.H., Panzara, M.A., Compston, D.A., 2012. Alemtuzumab versus interferon beta 1a as first-line treatment for patients with relapsing-remitting multiple sclerosis: a randomised controlled phase 3 trial. Lancet 380(9856), 1819-1828. 
Coles, A.J., Boyko, A.N., De Seze, J., Hartung, H.P., Havrdova, E., Inshasi, J.S., McCombe, P., Montalban, X., Pozzilli, C., Selmaj, K.W., Vermersch, P., Margolin, D.H., Daizadeh, N., Rodriguez, C.E., Van Wijmeersch, B., 2017a. Alemtuzumab Durably Improves Clinical Outcomes in Patients With Active RRMS in the Absence of Continuous Treatment: 7-Year Follow-up of CARE-MS I Patients (TOPAZ Study). Presented at: 7th Joint European Committee for Treatment and Research in Multiple Sclerosis (ECTRIMS)-Americas Committee for Treatment and Research in Multiple Sclerosis (ACTRIMS) Meeting, 25-28 October 2017; Paris, France. Abstract P1188.

Coles, A.J., Cohen, J.A., Fox, E.J., Giovannoni, G., Hartung, H.P., Havrdova, E., Schippling, S., Selmaj, K.W., Traboulsee, A., Compston, D.A.S., Margolin, D.H., Thangavelu, K., Chirieac, M.C., Jody, D., Xenopoulos, P., Hogan, R.J., Panzara, M.A., Arnold, D.L., 2017b. Alemtuzumab CARE-MS II 5-year follow-up: efficacy and safety findings. Neurology 89(11), 1117-1126.

Coles, A.J., Compston, D.A., Selmaj, K.W., Lake, S.L., Moran, S., Margolin, D.H., Norris, K., Tandon, P.K., 2008. Alemtuzumab vs. interferon beta-1a in early multiple sclerosis. N Engl J Med 359(17), 1786-1801.

Coles, A.J., Twyman, C.L., Arnold, D.L., Cohen, J.A., Confavreux, C., Fox, E.J., Hartung, H.P., Havrdova, E., Selmaj, K.W., Weiner, H.L., Miller, T., Fisher, E., Sandbrink, R., Lake, S.L., Margolin, D.H., Oyuela, P., Panzara, M.A., Compston, D.A., 2012. Alemtuzumab for patients with relapsing multiple sclerosis after disease-modifying therapy: a randomised controlled phase 3 trial. Lancet 380(9856), 1829-1839. 
Havrdova, E., Arnold, D.L., Cohen, J.A., Hartung, H.P., Fox, E.J., Giovannoni, G., Schippling, S., Selmaj, K.W., Traboulsee, A., Compston, D.A.S., Margolin, D.H., Thangavelu, K., Rodriguez, C.E., Jody, D., Hogan, R.J., Xenopoulos, P., Panzara, M.A., Coles, A.J., 2017. Alemtuzumab CARE-MS I 5-year follow-up: Durable efficacy in the absence of continuous MS therapy. Neurology 89(11), 1107-1116.

Hu, Y., Turner, M.J., Shields, J., Gale, M.S., Hutto, E., Roberts, B.L., Siders, W.M., Kaplan, J.M., 2009. Investigation of the mechanism of action of alemtuzumab in a human CD52 transgenic mouse model. Immunology 128(2), 260-270.

Le Page, E., Veillard, D., Laplaud, D.A., Hamonic, S., Wardi, R., Lebrun, C., Zagnoli, F., Wiertlewski, S., Deburghgraeve, V., Coustans, M., Edan, G., 2015. Oral versus intravenous high-dose methylprednisolone for treatment of relapses in patients with multiple sclerosis (COPOUSEP): a randomised, controlled, double-blind, non-inferiority trial. Lancet 386(9997), 974-981.

Lenz, H.J., 2007. Management and preparedness for infusion and hypersensitivity reactions. Oncologist 12(5), 601-609.

McEwan, L., Caon, C., Chieffe, C., Mayer, L., Saldana-King, T., Miller, C.E., 2016. Best Practices in Alemtuzumab Administration: Practical Recommendations for Infusion in Patients With Multiple Sclerosis. J Infus Nurs 39(2), 93-104.

Ruck, T., Bittner, S., Wiendl, H., Meuth, S.G., 2015. Alemtuzumab in Multiple Sclerosis: Mechanism of Action and Beyond. Int J Mol Sci 16(7), 16414-16439.

Singer, B.A., Alroughani, R., Brassat, D., Broadley, S., Hartung, H.P., Havrdova, E., Kim, H.J., Oreja-Guevara, C., Pozzilli, C., Selmaj, K.W., Vermersch, P., Wray, S., 
Margolin, D.H., Daizadeh, N., Chirieac, M.C., Coles, A.J., 2017. Durable Improvements in Clinical Outcomes With Alemtuzumab in Patients With Active RRMS in the Absence of Continuous Treatment: 7-Year Follow-up of CARE-MS II Patients (TOPAZ Study). Presented at: 7th Joint European Committee for Treatment and Research in Multiple Sclerosis (ECTRIMS)-Americas Committee for Treatment and Research in Multiple Sclerosis (ACTRIMS) Meeting; 25-28 October 2017; Paris, France. Abstract P736.

Turner, M.J., Pang, P.T., Chretien, N., Havari, E., LaMorte, M.J., Oliver, J., Pande, N., Masterjohn, E., Carter, K., Reczek, D., Brondyk, W., Roberts, B.L., Kaplan, J.M., Siders, W.M., 2015. Reduction of inflammation and preservation of neurological function by anti-CD52 therapy in murine experimental autoimmune encephalomyelitis. J Neuroimmunol 285, 4-12.

Ziemssen, T., Thomas, K., 2017. Alemtuzumab in the long-term treatment of relapsingremitting multiple sclerosis: an update on the clinical trial evidence and data from the real world. Ther Adv Neurol Disord 10(10), 343-359. 